\title{
St John's wort extract (Ze 117) does not alter the pharmacokinetics of a low-dose oral contraceptive
}

\author{
Liane Will-Shahab • Steffen Bauer • Ullrich Kunter • \\ Ivar Roots • Axel Brattström
}

Published online: 28 March 2009

(C) Springer-Verlag 2009

Erratum to: Eur J Clin Pharmacol (2009) 65:287-294 DOI 10.1007/s00228-008-0587-2

The original version of this article unfortunately contained a couple of mistakes.

In the Results section of the Abstract, the last sentence should read: "The mean of individual ratios (reference-totest) of log-transformed AUC values (90\% confidence interval) were $0.951(0.915-0.986)$ for ethinylestradiol and 0.968 (0.944-0.992) for ketodesogestrel indicating a small gain in bioavilability, but bioequivalence nevertheless."

The last sentence of the caption for Fig. 2 should read: "Closed circles indicate the baseline, open circles indicate values after 14 days of application of Ze 117."

The online version of the original article can be found at http://dx.doi. org/10.1007/s00228-008-0587-2.

\footnotetext{
L. Will-Shahab · U. Kunter BIOPHARM,

Bitterfelder Str. 19,

12681 Berlin, Germany

S. Bauer - I. Roots

Institute of Clinical Pharmacology,

University Medical Centre Charité,

Humboldt University of Berlin,

Schumannstr. 20/21,

10098 Berlin, Germany

\author{
A. Brattström $(\square)$ \\ Max Zeller \& Söhne AG, \\ Seeblickstrasse 4, \\ CH-8590 Romanshorn, Switzerland \\ e-mail: axel.brattstroem@zellerag.ch
}

